\title{
Millaista kieltä suomalainen sivistyneistö puhui?
}

Jaakko Anhava (2019) esitti viime Virittäjässä kysymyksen "Puhuiko Suomen sivistyneistö kirjakieltä?" Koska hän osoitti sen erityisesti minulle aiempia kirjoituksiani lainaten, vastaan hänelle. Lyhyt vastaus on: osa puhui, osa ei. Kysymys on kuitenkin tulkinnanvarainen.

Myönnän, että olen Anhavan lainaamissa kirjoituksissa (Paunonen 1993, 1994) osin oikonut mutkia. Olisi ollut paikallaan erottaa selvemmin oikeakielisyysmiesten sivistyneistön puhekielelle asettamat ihanteelliset tavoitteet siitä kielestä, jota suomalainen sivistyneistö on 1860-1960-luvuilla puhunut. Niin olen myöhemmin tehnytkin: "Tavoitteeksi asetettiin sellaisen puhtaan suomen kielen kehittäminen, joka samalla kertaa toimisi sekä suomalaisuuden symbolina että kansallisena yhdistäjänä" (Paunonen 2006: 45).

Anhava tuo kirjoituksessaan esiin sen, että hänen isoäitiensä puhe oli "arkista, osin murreväritteistä yleissuomea". Samanlaista suomea ovat käyttäneet monet muutkin hänen eri puolilla Suomea syntyneet ja osin asuneetkin sukulaisensa.

Yleistäen Anhavan näkökulmana on murteellisuuksien esiintyminen sivistyneistön puhekielessä. Hänen esittämäänsä kysymykseen liittyy toinenkin näkökulma: millaista suomea ovat aikanaan käyttäneet kielenvaihtajat? Tarkoitan kielenvaihtajilla niitä suomalaisen sivistyneistön jäseniä, joiden alkuperäinen äidinkieli oli jokin muu kuin suomi, tavallisimmin ruotsi, mutta toisinaan myös saksa tai venäjä.

Ensimmäisiä kielenvaihtajaperheitä, joissa otettiin suomi kotikieleksi, olivat Yrjö Koskisen ja Julius Krohnin per- heet 1850-luvulla ja 186o-luvun alkupuolella, mutta kielenvaihtajien määrä alkoi nopeasti kasvaa 1870-luvulta lähtien, ja kielenvaihtoa tapahtui vielä 1920-1930-luvuille asti. Helsingissä kielenvaihtajaperheiden lapset kävivät usein Suomalaista Yhteiskoulua. (Paunonen 2006: 28-32.)

\section{Miten suomalaisen sivistyneistön tuli puhua?}

Huomattava osa nuoren suomalaisen sivistyneistön jäsenistä asui ainakin opiskeluaikansa Helsingissä, missä oli yliopisto. Heidän kannaltaan ongelmana oli se, että vielä 180o-luvun puolivälissä Helsinki oli lähes ruotsinkielinen kaupunki. Varsinkin säätyläiset ja ylempi porvaristo olivat ruotsinkielisiä. Vaikka suomen kirjakieli alkoi niihin aikoihin olla hahmollaan, sitä vastaava puhekieli puuttui. Tähän seikkaan kiinnitettiin huomiota Suomettaressa jo 1847: "Suomen kieli vielä ei ole' saanut sivistyneiden yhteistä murretta, kuin sivistyneet vielä eivät paljon käytäkkään suomea puhe'kielenänsä”' (Suometar 1847).

Suomenkielisen sivistyneistön puhekieli oli usein esillä Kotikielen Seurassa. Se oli pääaiheena jo seuran ensimmäisessä kokouksessa maaliskuussa 1876 . Silloin lueteltiin varsinkin sellaisia piirteitä, jotka itäsuomalaisten ylioppilaiden tulisi karsia puheestaan (Paunonen 1976: 336). Kolme vuotta myöhemmin August Ahlqvist tiivisti saman seuran kokouksessa kantansa murteellisuuksiin toteamalla, ettei talonpoikien murteellinen puhe loukkaa kuulijaa, mutta "parempihan on, että sivistyneet puhuvat niin liki kirjakieltä 
kuin sopii" (mts. 336-337). Kymmenen vuotta myöhemmin hän kirjoitti: "Jos kukaan, olen minä sekä kirjallisesti että suullisesti vastustanut liiallista maakuntalaisuutta sekä murrerakkautta, olletikin itäsuomalaista." (Ahlqvist 1887: 5; Kohtamäki 1956: 65.)

Ahlqvist asetti näin nuoren suomenkielisen sivistyneistön ideaaliseksi malliksi sellaisen puhekielen, joka oli "niin liki kirjakieltä kuin sopii”.

\section{Murteellisuuksien kitkeminen sivistyneistön puhekielestä}

Ahlqvist suhtautui murteellisuuksiin yhtä torjuvasti kuin "muukalaisuuksiin", joilla hän tarkoitti vieraiden kielten vaikutusta suomeen. Niille ei ollut sijaa sivistyneistön puhekielessä. Arvid Järnefelt on kuvannut tämän periaatteen vaikutusta oman perheensä käyttämään kieleen:

Helsinkiin [Viipurista vuonna 1870] muutettuamme oli Aleksanderin ensimmäisenä huolena ollut perheensä suomenkielentaidon edistäminen ja moitteettomaksi saattaminen. Oli vapauduttava siitä epäkirjallisesta murteesta, joka oli Viipurissa tarttunut sekä Elisabetiin että meihin. Sillä nyt oli välttämätöntä omata suomalainen kirjakieli, jota paraikaa vielä luotiin ja jonka oli oltava Suomen erikoisena sivistyskielenä. Sivistyneen säädyn tunnusmerkkinä oli oleva, että se puhui tätä kirjakieltä eikä murteita, jotka edustivat 'sivistymättömiä. Ei siis mitenkään enää 'mie,' 'miun', 'veissi', 'messässä, niinkuin Viipurissa puhuttiin, vaan selvästi: minä, meidän, veitsi, metsä. (Järnefelt 1960 [1928-1930]: 284.)

Järnefeltin kuvauksessa on huomionarvoista se, että murteellisen puhekielen vaihtaminen kirjakieliseen puhetapaan liittyi perheen muuttoon Viipurista Hel- sinkiin. Helsingissä oli puhuttava kirjakielisesti, kun taas Viipurissa oli käytetty murteellisempaa puhekieltä. Helsingissä murteellinen puhekieli oli sosiaalisesti leimautunutta, ja sitä puhuttiin työläiskaupunginosissa.

Kuitenkin jo vuonna 1876 itäsuomalaiset ylioppilaat olivat vastustaneet Kotikielen Seurassa kirjakielisen $d$ :n käyttöpakkoa sivistyneessä puhekielessä. Samaan seikkaan palattiin seuran kokouksissa usein myöhemminkin. Vuonna 1900 seuran itäsuomalaiset jäsenet vakuuttivat, että "heikäläisten on miltei mahdotonta oppia ääntämään $d$ :tä ruotsin mukaan puheäänelliseksi”. (Paunonen 1976: 338.) Lauri Kettunen (1909, 1910) jatkoi $d$ :n vastaista taistelua Virittäjässä vielä 1900-luvun alussa. Kirjoituksessaan Väärä suhteemme kirjakieleen Kettunen mainitsi, etteivät monet itäsuomalaiset edes halunneet opetella kirjakieleen perustuvaa yleiskieltä, koska sen ääntäminen tuotti heille "voittamattomia luonnonesteitä". Syykin oli selvä: "Onhan siinä äänne, vieläpä pahaksi onneksi toistumiseensa toistuva äänne, joka puheelle antaa kansankielen kannalta arvioituna luonnottoman, keinotekoisen leiman, on tuo työläästi opittava, ruotsalaisuudelta peritty $d$. .' (Kettunen 1910: 57-58.)

Kettusen havainnot tukevat sitä, mitä Anhava kertoo eri puolilla Suomea asuneiden sukulaistensa kielestä. Helsingin ulkopuolella, suomenkielisillä alueilla on käytetty enemmän tai vähemmän murteellista puhekieltä. Silti tavoitteeksi kouluopetuksessa asetettiin jo varhain kirjakielen opettaminen oppilaille heti alusta lähtien. Tampereella järjestettiin 8.-9.10.1889 Hämeen läänin kansakoulunopettajien piirikokous, jonka esityslistalla kysymys numero 14 kuului: "Onko siinä kylliksi, että oppilaat ainoastaan opetetaan tuntemaan puhdasta eli niin sanottua kirjakieltä, vai onko vaadittava, että he niin paljon kuin mahdollista sitä puheessaan käyttävät?” (Tampereen Sanomat 9.10.1889.) 


\section{"Ruotsi runnellut" Helsingissä puhutun suomen}

Helsingissä murteita suurempi ongelma oli kuitenkin se, että kaupungin hallitseva kieli oli ruotsi ja että melko pitkään merkittävä osa suomalaisesta sivistyneistöstä tuli ruotsinkielisistä kodeista. Heille suomi oli alkuaan vieras tai toinen kieli. Sillä perusteella, mitä tiedämme nykyisin suomea toisena kielenä puhuvien suomesta, voimme olettaa, että kielenvaihtajien äidinkieli on monella tavoin heijastunut heidän puhumaansa suomeen.

Valitettavasti tästä vaiheesta on säilynyt aika vähän tarkempia yksityiskohtia. Kuitenkin Kotikielen Seurassa vuonna 1890 "neiti I. Hannikainen piti huvittavan esitelmän Helsingin suomesta huomauttaen siinä, kuinka ruotsinkieli oli runnellut varsinkin lausumatavan suomea puhuvalta väestöltä pääkaupungissa" (Paunonen 1976: 383). On harmillista, että pöytäkirja on niin lakoninen, ettei näitä "huvittavia" lausumatapoja ole kirjattu siihen tarkemmin.

Aineistoa löytyy kuitenkin välillisesti. Vuonna 1872 perustetun Suomalaisen Teatterin näyttelijöiden kieltä on arvioitu ja arvosteltu varsin kriittisesti heti alkuvuodesta 1873 lähtien. Suuri osa Suomalaisen Teatterin ja vielä Kansallisteatterinkin näyttelijöistä oli kotoisin ruotsinkielisistä perheistä, ja heidän suomen kielen taitonsa oli puutteellista. Vuonna 1885 Kotikielen Seurassa kiinnitettiin huomiota siihen, että näyttelijät äänsivät geminaattakonsonantit ja painottomien tavujen pitkät vokaalit usein lyhyinä, esimerkiksi heitää, kiitää, otta, anta pro heittää, kiittää, ottaa, antaa (Paunonen 1976: 337). Samantapaisia havaintoja oli myös nimimerkillä "p": monta kerta, sano suoran, toollaisella loonteella, veekkain meelin (Uusi Suometar 10.4.1886). Vielä 1913 Viljo Tarkiaisen mukaan Kansallisteatterin näyttelijöistä Axel Ahlberg äänsi pitkiä vokaaleja ja geminaattakonsonantteja lyhyinä. Yksittäi- sistä äänteistä Tarkiainen kiinnitti huomiota naisnäyttelijöiden epäsuomalaiseen

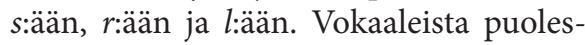
taan $a$ ääntyi toisinaan liian etisenä ja $u$ ruotsalaisittain $u$ :na: hullu, mitä sinulle kшulum, hautaan saakka. (Tarkiainen 1913: 154-155).

Kielenvaihtajien ja kaksikielisten suomen kieltä kuvaili kriittisin korvin esimerkiksi Vihtori Peltonen eli Johannes Linnankoski:

Katsahtakaa ympärillenne ja kuunnelkaa! Kuunnelkaa niiden kieltä, joille on yhdentekevää kumpaa he puhuvat, suomea tai ruotsia, ja te huomaatte hämmästykseksenne, jos oma korvanne vain on vielä suomalainen, että heidän suomenkielensä on lauserakenteeltaan läpeensä ruotsalaista ja ruotsalaisia sanontatapoja täynnä. [- - Kuunnelkaa niiden kieltä, joilla ei ole mitään 'äidinkieltä, vaan jotka taitavat molempia 'yhtä hyvin' - pian huomaatte, etteivät he taida varmasti mitään kieltä! Ja sellaisia meillä on satoja. (Peltonen 1906.)

Helsinkiläisten huonoon kielikorvaan on viitattu vuosikymmenten ajan. Itse muistan, että vielä 1950-luvulla monet vanhemmat ja varsinkin muualta Suomesta Helsinkiin muuttaneet puhuivat usein helsinkiläisten huonosta kielikorvasta. Minäkin sain siitä kerran kotona osani, kun menin kysymään isältäni: "Ketä tuo setä oli?"

En puutu tässä tarkemmin suomalaisen sivistyneistön kotona käyttämään kyökkisuomeen. Sen kitkeminen vei vuosikymmeniä, ja siinä olivat keskeisiä toimijoita ensin Kodin sanaston tekijät Ilmi Hallstén ja Lilli Lilius (1896). Myöhemmin kyökkisuomen vastaista taistelua johtivat Johannes Linnankoski ja varsinkin Maila Talvio (Peltonen 1906; Talvio 1909a, 1909b, 1916). Kyökkisuomea ei käytetty vain helsinkiläisissä säätyläiskodeissa vaan kaikkialla Suomessa, mutta sekin oli varsin 
kaukana puhtaan suomalaisen puhekielen ihanteesta (Paunonen 2006: 60-62).

\section{Puhuiko Suomen sivistyneistö kirjakieltä?}

Palaan vielä Anhavan esittämään kysymykseen Helsingin puhekielen tutkimusaineiston valossa. Tutkimushankkeessa on haastateltu eri-ikäisiä helsinkiläisiä kolmena vuosikymmenenä: 1970-luvulla, 1990-luvulla ja 2010-luvulla. 1970-luvun informanteista yhden, vuonna 1905 syntyneen akateemisen töölöläisnaisen kirjakielisyysprosentti oli 25 kielenpiirteen perusteella täydet 100. Hän puhui "täydellistä" kirjakieltä. (Paunonen 2006: 71; 2017.)

Huomattavan monet vanhemmat ja keski-ikäiset helsinkiläiset ovat näissä ja muissa haastatteluissa sanoneet puhuvansa kirjakieltä. Esimerkiksi vuonna 1927 syntynyt akateeminen töölöläisnainen kertoi haastattelijalle omasta puhekielestään: "siis meil oli ilman muuta selvää, että siis puhutaan, puhutaan kirjakieltä." Silti hänen kirjakielisyysprosenttinsa oli 1970-luvun haastattelussa "vain" 68. (Paunonen 2006: 74; 2017.) Näyttää siltä, että suomalainen sivistyneistö on puhunut kirjakielisimmin 1920-1950-luvuilla.

Monilla helsinkiläisillä on ollut se mielikuva, että he puhuvat kirjakieltä, vaikka mukaan mahtuisi puhekielisyyksiä. Kirjakielisimmin puhuvilla ei juuri ole puhekielisyyksiä esimerkiksi $d: n$ tai ts:n vastineissa, mutta sitä vastoin verbien persoonakongruenssissa niitä saattaa olla. Samoin heillä esiintyy melko usein lausefoneettista loppuheittoa (meilloli). Omasta mielestään kirjakielisesti puhuvat helsinkiläiset ovat sijoittuneet ja sijoittuvat vieläkin melko laajalle harmaalle alueelle, sikäli kuin heitä enää on tavoitettavissa. Itse kuulun edelleen siihen joukkoon, vaikka puheeni ei olekaan sataprosenttisesti kirjakielistä.

Anhavan kysymykseen vastattaessa on erotettava ne puhujat, jotka ovat todella puhuneet kirjakieltä, ja ne puhujat, jotka ovat omasta ja usein toistenkin mielestä puhuneet kirjakieltä. Olisikin mielenkiintoista seuloa ne Helsingin puhekielen piirteet, jotka ovat olleet niin puhujien kuin kuulijoidenkin mielestä kirjakielisen puhekielen avaintuntomerkkejä. Ainakin kirjakielen $d$ ja ts kuuluvat niihin samoin kuin monikon 1. ja 3. persoonan kongruenssikin, esimerkiksi $(m e)$ menemme, lapset leikkivät pro me mennään, lapset leikkii. Mielenkiintoinen kysymys on myös se, kuinka laaja kirjakielisesti omasta mielestään puhuneiden harmaa alue on todellisuudessa ollut.

Viittaan vielä lopuksi Anhavan tapaan omaan perheeseeni. Isäni oli kotoisin Säämingistä. En muista koskaan kuulleeni, edes harjaantuneella kielentutkijan korvallani, että hän olisi käyttänyt yhtäkään savolaismurteille ominaista piirrettä puheessaan. Isäni oli valmistunut 1940-luvun lopussa Helsingin yliopistosta filosofian maisteriksi. Minunkin kieltäni kotona korjattiin, ja varsinkin kaikki slangisanat olivat pannassa.

\section{Heikki Paunonen etunimi.sukunimi@kolumbus.fi \\ Kirjoittaja on suomen kielen professori emeritus.}

\section{Lähteet}

Ahlqvist, August 1887: Kalevalan Karjalaisuus. Kalevalasta itsestään ja muualta todistanut Aug. Ahlqvist. Helsinki: J. C. Frenckell ja Poika.

Anhava, JaAkкo 2019: Puhuiko Suomen sivistyneistö kirjakieltä? - Virittäjä 123 s. 443-445.

Hallstén, Ilmi - Lilius, Lilli 1896: Kodin sanasto. Helsinki: Werner Söderstöm.

Järnefelt, ARVID 1960 [1928-1930]: Vanhempieni romaani. Kolmas painos. Porvoo-Helsinki: Werner Söderström Osakeyhtiö. 
Kettunen, Lauri 1909: Suhteemme kirjakieleen. - Virittäjä 13 s. 165-168.

— 1910: Väärä suhteemme kirjakieleen. - Virittäjä 14 s. 57-63.

Контамӓкі, Ilmari 1956: Ankara puutarhuri. August Ahlqvist suomen kielen ja kirjallisuuden arvostelijana. Helsinki: Suomalaisen Kirjallisuuden Seura.

Paunonen, Heik i 1976: Kotikielen Seura 1876-1976. - Virittäjä 8o s. 310-432.

— 1993: Suomen mieli - oikea kieli. - Virittäjä 97 s. 81-88.

_ 1994: Kielen normit ja kielen ohjailun normit. - Tiede \& edistys 1/1994 s. 17-28.

— 2006: Vähemmistökielestä varioivaksi valtakieleksi. - Kaisu Juusela \& Katariina Nisula (toim.), Helsinki kieliyhteisönä s. 13-99. Helsinki: Helsingin yliopiston suomen kielen ja kotimaisen kirjallisuuden laitos.
_ 2017: Suomen kieli Helsingissä 1917 ja 2017. Plenaariesitelmä Kielitieteen päivillä 20.5.2017. Jyväskylä.

Peltonen, Vihtori 1906: Mitä suomenkieli suomalaisilta vaatii? - Uusimaa 13.8.1906.

Suometar $1847=$ Suomen kieli kirjallisesti' käytettävänä. - Suometar 11.5.1847.

Talvio, Maila 1909a: Puhe [fennomaanien Nuija-yhdistyksessä]. - Uusi Suometar 18.4.1909.

_ 1909b: Hiukan meistä ja kielestämme. - Uusi Suometar 17.11.1909.

_ 1916: Meidän kielemme. - Suomalainen Suomi 1916 s. 116-125.

Tampereen Sanomat 9.10.1889. Tampere.

TARkiAinen, Viljo 1913: Suomenkielen lausumisesta näyttämöillämme. - Näyttämötaide 1913 n:o 8 s. 153-158.

Uusi Suometar 10.4.1886. Helsinki.

\section{Kyllä kirjakieltä puhuttu on}

Jaakko Anhava (2019) kyseenalaistaa tiedon, että Suomen sivistyneistö olisi jossain historian vaiheessa puhunut kirjakieltä. Hän katsoo minun kaiuttavan kirjassani (Lyytikäinen 2016) tätä Heikki Paunosen monissa tutkimuksissaan esiin tuomaa tulosta. Anhavalla on avaintodistajina molemmat isoäitinsä ja isotäti, jotka kaikki ovat työskennelleet opettajina. Käytän samaa metodia ja astun todistajanaitioon.

Olen syntynyt Kymin Karhulassa 1942 ja käynyt siellä kouluni vuosina 1949-1961. Kaikki opettajat - he olivat oppilaitaan sukupolven, pari vanhempia - puhuivat kirjakieltä. Kirjakieli oli minulle aluksi vaikeaa, koska se sisälsi vierasta sanastoa ja morfologiaa, mutta pian siihen tottui.

Kansakoulussa opettajat eivät juuri pyrkineet vaikuttamaan oppilaittensa puheeseen, oppikoulussa sen sijaan pyrkivät, hienovaraisin tai suorin keinoin. Matematiikan opettaja ei sietänyt ilmausta sil- viisii 'sillä tavoin'. Se oli hänen mielestään karkeata murretta. Äidinkielen opettaja neuvoi eksplisiittisesti: "Täällä oppikoulussa ja ainakin äidinkielen tunneilla me puhumme kirjakieltä."

Ehkäpä opettajat suolsivat institutionaalista kieltä, roolipuhetta. En tiedä, miten he ompelu- ja metsästysseuroissaan, kotioloissaan tai ryyppyporukoissa juttelivat, mutta jos ihminen ilmaisee itseään kirjakielellä joka arkipäivä (myös lauantaisin) monta tuntia päivässä, se jättää jälkensä hänen persoonallisuuteensa. Kyllä häntä voi nimittää kirjakielen puhujaksi. Esittelen lisää lapsuuteni kirjakielimaisemaa pian ilmestyvässä teoksessa Sehän on murretta! (Lyytikäinen 2020).

Akateeminen opettajani ja esimieheni, professori, akateemikko Pertti Virtaranta (1918-1997) puhui kirjakieltä. Olen kuvannut hänen kateederikieltään (Lyytikäinen 2018: 125), mutta myös hänen ar- 